\title{
Regulasi Emosi Remaja dari Ibu Pekerja Migran dan Non Migran
}

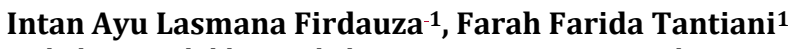

1Fakultas Pendidikan Psikologi Universitas Negeri Malang

DOI: http://doi.org/10.29080/ipp.v12i1.506

Abstract : Emotional regulation is the ability to manage or control emotions. Many teenagers who cannot manage their emotions effectively are prone to depression. This study aims to compare emotional regulation of cognitive reappraisal and expressive suppression among teenagers. Having comparative quantitative methods, this study involved 101 respondents who were selected through purposive technique sampling. Data were collected using an ERQ (Emotion Regulation Questionnaire) scale consisting of 10 questions and then analyzed with an independent sample t-test. The results showed that there was a significant difference in expressive suppression but there was no difference in cognitive reappraisal. The implication of this research shows the importance of mothers who are migrant workers to maintain their interactions with their children. Quality and quantity of interaction between mother and children can be used in further research.

Keywords : emotion regulation strategies, migran worker mothers, teenagers

Abstrak : Regulasi emosi merupakan kemampuan individu dalam mengelola atau mengontrol emosi. Banyak remaja yang tidak dapat mengelola emosi mereka secara efektif sehingga rentan terhadap depresi. Penelitian ini bertujuan untuk membandingkan regulasi emosi cognitive reappraisal dan expressive suppression pada remaja. Menggunakan metode kuantitatif komparatif, penelitian ini melibatkan 101 responden yang dipilih melalui purposive technique sampling. Pengumpulan data menggunakan skala ERQ (Emotion Regulation Questionnaire) yang terdiri dari 10 pertanyaan dan selanjutnya dianalisis dengan independent sample t-test. Hasil penelitian menunjukkan bahwa ada perbedaan yang signifikan pada expressive suppression namun tidak ada perbedaan pada cognitive reappraisal. Implikasi penelitian ini menunjukkan pentingnya para ibu yang menjadi pekerja migran untuk tetap menjaga interaksi dengan anaknya. Faktor kualitas dan kuantitas interaksi antara ibu dan anak dapat menjadi bahan penelitian selanjutnya.

Kata kunci : strategi regulasi emosi, ibu pekerja migran, remaja

Field Code Changed

Formatted: Font: Cambria 


\section{Pendahuluan}

Regulasi emosi dapat diartikan sebagai kemampuan mengelola atau mengontrol emosi. Menurut Gross (2006) regulasi emosi adalah pengaturan emosi yang mengacu pada serangkaian proses. Setiap individu memiliki cara masing-masing dalam meregulasi emosi. Emosi adalah hasil reaksi kognitif terhadap situasi spesifik. Mayoritas remaja belum dapat mengelola emosi mereka dengan efektif sehingga rentan mengalami depresi. Remaja yang kurang bisa mengekspresikan emosi dengan tepat cenderung terlibat dalam masalah hingga memiliki intensi bunuh diri.

Regulasi emosi yang buruk pada remaja dapat memicu sejumlah masalah seperti penyalahgunaan narkoba, kenakalan remaja, hingga gangguan makan (Santrock, 2013). Masalah-masalah terkait kenakalan remaja menurut Lamb dan Freund (2010) dianggap sebagai hasil dari keterbatasan perkembangan masa remaja dalam segi perkembangan emosinya. Penelitian yang dilakukan oleh Septiawan (2019) juga menunjukkan bahwa semakin baik regulasi emosi yang dimiliki siswa maka semakin rendah tingkat kenakalan remaja pada siswa sekolah menengah pertama.

Perkembangan pada masa remaja merupakan tahapan yang ditandai oleh banyak perubahan drastis. Masa remaja disebut sebagai masa storm and stress, yaitu masa bergejolak yang diwarnai oleh konflik dan perubahan suasana hati. Remaja bisa tampak senang pada suatu waktu dan tampak sangat sedih pada waktu yang lainnya. Dalam banyak kasus yang terjadi, intensitas emosi mereka tampak tidak proporsional dengan peristiwa yang mereka alami (Santrock, 2013). Sifat dan intensitas emosi biasanya berkaitan erat dengan aktivitas kognitif manusia sebagai hasil persepsi terhadap situasi.

Faktor yang dapat mempengaruhi regulasi emosi adalah perbedaan individu dalam temperamen, attachment dan juga pola pengasuhan yang dimiliki (Gross, 2006). Peran orang tua sebagai pengasuh utama sangat diperlukan bagi para remaja. Penelitian Silitonga (2015) menjelaskan bahwa peran orangtua memiliki hubungan yang signifikan dengan perkembangan emosional remaja. Pola asuh yang dilakukan oleh orangtua satu dengan yang lainnya tentu tidak sama dan itu akan berdampak pada perkembangan emosional remaja.

Meskipun peran keluarga atau orangtua menjadi konteks utama dalam perkembangan manusia, namun ada faktor lain di luar keluarga yang juga dapat berpengaruh. Menurut teori ekologi Bronfenbrenner perkembangan manusia dipengaruhi oleh beberapa system. Exosystem adalah salah satu sistem yang mana pekerjaan orangtua dan kebijakan dari pekerjaannya juga akan mempengaruhi perkembangan anaknya (Santrock, 2013). Para ibu pekerja migran membuat mereka harus tinggal terpisah dengan anaknya sehingga ank-anak memiliki pengalaman yang berbeda dibandingkan dengan mereka yang memiliki ibu bukan pekerja migran.

Pekerja Migran Indonesia dalam UU No. 18/2017 (Dalam Profil Perempuan Indonesia, 2019) merupakan warga negara Indonesia yang akan, sedang, atau telah melakukan pekerjaan dengan menerima upah di luar wilayah negara Republik Indonesia. Pekerja Migran Indonesia meliputi semua gender baik laki-laki maupun perempuan. Namun pekerja migran perempuan cenderung lebih banyak daripada laki-laki setiap tahunnya. Mayoritas pekerja migran adalah mereka yang telah berkeluarga sehingga konsekuensi yang mereka terima adalah meninggalkan keluarga. Ibu yang bekerja membuat mereka tidak dapat bersama keluarga sehingga pengasuhan anak dilakukan oleh ayah atau oleh anggota keluarga yang lain.

Pada kasus ibu yang memilih untuk bekerja sebagai pekerja migran, mereka otomatis meninggalkan anaknya untuk jangka waktu yang cukup lama bahkan sampai beberapa tahun. Konsekuensi yang diterima adalah pola asuh yang diterapkan akan berbeda dibandingkan dengan ibu yang bekerja dan pulang setiap hari ke rumah. Pengasuhan anak yang ibunya menjadi pekerja migran dialihkan kepada orang lain seperti

Formatted: Indonesian

Formatted: Indonesian

Formatted: Indonesian 
ayah, nenek, kakek, atau mungkin anggota keluarga lainnya. Hal itu tentunya berdampak pada perkembangan emosional anak.

Pengasuhan orangtua memiliki peran penting dalam perkembangan emosi pada remaja. Menurut Calkins (dalam Gross, 2006) interaksi yang terjadi dengan orangtua secara tidak langsung mengajarkan anak untuk menggunakan strategi tertentu dalam mengurangi gairah emosional. Garside dan Klimes-Dougan (2002) menyatakan bahwa ibu umumnya menjadi agen sosialisasi emosi yang aktif daripada ayah. Ibu lebih sering dalam membicarakan emosi daripada ayah. Penelitian yang dilakukan oleh Bariola, Gullone dan Hughes (2011) juga menunjukkan bahwa penggunaan strategi regulasi emosi tertentu terkait dengan penggunaan regulasi emosi pada anak. Seorang ibu yang menggunakan expressive suppression dalam meregulasi emosi berhubungan erat dengan expressive suppression pada sang anak.

Penelitian-penelitian terdahulu yang terkait regulasi emosi mengukur regulasi emosi secara lebih umum. Namun Gross dan John (2003) secara teoritis berfokus kepada dua strategi ketika membicarakan mengenai regulasi emosi, yaitu cognitive reappraisal dan expressive suppression. Cognitive reappraisal adalah suatu bentuk perubahan kognitif yang melibatkan penafsiran situasi yang berpotensi memunculkan emosi dengan cara mengubah dampak emosionalnya, sedangkan expressive suppression adalah bentuk modulasi respon yang melibatkan penghambatan perilaku ekspresif emosi yang berkelanjutan.

Cognitive reappraisal dan expressive suppression memiliki dampak yang berbeda. Cognitive reappraisal terjadi lebih awal sebelum respon emosi dihasilkan. Ketika meregulasi emosi negatif, cognitive reappraisal seharusnya berhasil untuk mengurangi pengalaman dan perilaku komponen emosi yang negatif. Sebaliknya, expressive suppression terjadi relatif lambat di akhir. Expressive suppression mungkin memiliki efek samping yang tidak diinginkan dan menekan emosi yang positif ketika digunakan sebagai strategi untuk meregulasi emosi negatif. Pada saat yang sama expressive suppression tidak membantu untuk mengurangi pengalaman emosi yang negatif akan tetapi hanya menekannya. Konsekuensi yang dikhawatirkan adalah emosi negatif itu akan terus bertumpuk dan tidak akan terselesaikan.

Sejumlah penelitian yang telah dirangkum oleh Varzeletti, Zammuner, Galli dan Agnoli (2016) menunjukkan bahwa cognitive reappraisal berkorelasi positif dengan kesehatan psikologis seperti kepuasan hidup, pengaruh positif, harga diri, dan hubungan sosial. Adapun expressive suppression dikaitkan dengan konsekuensi negatif dalam hal kognitif, afektif, kepuasan hidup, pengaruh negatif, dan risiko yang lebih tinggi dalam depresi dan kecemasan.

Berdasarkan uraian di atas peneliti ingin mengetahui apakah kehadiran maupun ketidakhadiran ibu secara fisik dengan anak remajanya berhubungan dengan perkembangan regulasi emosi remaja. Peneliti lebih khusus ingin membandingkan antara regulasi emosi cognitive reappraisal dan expressive suppression) pada remaja dari ibu seorang pekerja migran dan non-migran di Kabupaten Malang. Penelitian ini diharapkan dapat memberikan informasi terkait peran keluarga khususnya ibu yang bekerja dalam perkembangan emosi dan pengasuhan pada remaja.

\section{Metode Penelitian}

Metode yang digunakan dalam penelitian ini adalah kuantitatif komparatif. Regulasi emosi merupakan variabel terikat $(\mathrm{Y})$ dan remaja yang memiliki ibu pekerja migran dan non migran sebagai variabel bebas (X). Pemilihan sample dilakukan dengan menggunakan purposive technique sampling dimana responden dipilih berdasarkan kriteria tertentu. Sampel yang digunakan dalam penelitian ini berjumlah 101 responden yang terdiri dari 47 remaja yang memiliki ibu pekerja migran dan 54 remaja dengan ibu 
pekerja non migran di Kabupaten Malang. Pengolahan data menggunakan analisis data independent sample t-test dengan bantuan SPSS 26 for windows untuk menguji perbedaan rata-rata dari dua kelompok.

Instrumen penelitian yang digunakan dalam penelitian ini adalah kuesioner regulasi emosi yang diadaptasi dari skala regulasi emosi milik Gross dan John yaitu Emotion Regulation Questionnaire (ERQ). Skala tersebut diterjemahkan ke dalam bahasa Indonesia. Kuesioner berisi 10 pertanyaan yang terdiri dari strategi cognitive reappraisal dan expressive suppression. Strategi cognitive reappraisal berjumlah 6 aitem dan strategi expressive suppression berjumlah 4 aitem. Kuesioner ini menggunakan skala 1 - 7 dimulai dari "Sangat Tidak Setuju" sampai dengan "Sangat Setuju".

\section{Hasil Penelitian}

Hasil analisis data pertama menampilkan diskripsi nilai rata-rata pada tiap strategi dan tiap kelompok sampel yang dapat dilihat pada tabel 1.

Tabel 1

Hasil Skor Rata-rata Strategi Regulasi Emosi

\begin{tabular}{ccccc}
\hline \multirow{2}{*}{ Perbandingan } & \multicolumn{2}{c}{$\begin{array}{c}\text { Ibu Pekerja Migran } \\
(\mathrm{N}=47)\end{array}$} & \multicolumn{2}{c}{$\begin{array}{c}\text { Ibu Pekerja Non Migran } \\
(\mathrm{N}=54)\end{array}$} \\
\cline { 2 - 5 } & Mean & SD & Mean & SD \\
\hline Cognitive Reappraisal & 31.49 & 7,321 & 32.69 & 5.269 \\
\hline Expressive Suppression & 20.06 & 4.780 & 18.13 & 4.404 \\
\hline
\end{tabular}

Nilai mean dari cognitive reappraisal pada remaja dari ibu pekerja migran sebesar 31,49 $[\mathrm{SD}=7,321]$ dan nilai mean pada remaja dari ibu pekerja non migran sebesar 32,69 [SD = 5 , 269]. Adapun nilai mean strategi expressive suppression adalah $20,06[\mathrm{SD}=4,780]$ untuk remaja dari ibu sebagai pekerja migran dan 18,13 [SD $=4,404$ ] untuk remaja dari ibu pekerja non migran

Selanjutnya statistik parametris independent sample t-test digunakan untuk menguji perbedaan strategi cognitive reappraisal antara dua kelompok responden.

Tabel 2

Hasil t-test Perbedaan Cognitive Reappraisal

\begin{tabular}{|c|c|c|c|c|}
\hline t & df & Sig. (2-tailed) & Mean Difference & Std. Error Difference \\
\hline-.951 & 99 & .344 & -1.196 & 1.258 \\
\hline
\end{tabular}

Hasil dari uji perbedaan pada strategi cognitive reappraisal berdasarkan tabel 2 menunjukkan bahwa tidak ada perbedaan regulasi emosi menggunakan strategi cognitive reappraisal pada remaja dari ibu yang bekerja sebagai pekerja migran dan remaja yang memiliki ibu sebagai pekerja non migran. Asumsi dari teknik independent sample t-test adalah apabila signifikansi $<0,05$ maka menunjukkan adanya perbedaan, sebaliknya jika signifikansi $>0,05$ maka menunjukkan tidak ada perbedaan. Signifikansi strategi cognitive reappraisal dapat dilihat pada tabel 2 . Signifikansi pada strategi cognitive reappraisal adalah sebesar 0,344 dimana $>0,05$ maka disimpulkan tidak ada perbedaan yang signifikan pada strategi regulasi emosi cognitive reappraisal pada remaja dari ibu pekerja migran dan non migran.

Hasil analisis berikutnya adalah uji perbedaan strategi expressive suppression yang juga dilakukan menggunakan independent sample t-test. 
Tabel 3

Hasil t-test Perbedaan Expressive Suppression

\begin{tabular}{lllll}
\hline $\mathbf{t}$ & $\mathbf{d f}$ & Sig. (2-tailed) & Mean Difference & Std. Error Difference \\
\hline 2.116 & 99 & .037 & 1.934 & .914 \\
\hline
\end{tabular}

Hasil dari uji perbedaan pada strategi expressive suppression berdasarkan tabel 3 menunjukkan bahwa ada perbedaan regulasi emosi menggunakan strategi expressive suppression pada remaja dari ibu yang bekerja sebagai pekerja migran dan remaja yang memiliki ibu sebagai pekerja non migran. Asumsi dari teknik independent sample t-test adalah apabila signifikansi $<0,05$ maka menunjukkan adanya perbedaan, sebaliknya jika signifikansi $>0,05$ maka menunjukkan tidak ada perbedaan. Signifikansi strategi expressive suppression dapat dilihat pada tabel 3. Signifikansi pada strategi expressive suppression adalah sebesar 0,037 dimana $<0,05$ maka dapat disimpulkan ada perbedaan yang signifikan pada strategi regulasi emosi expressive suppression pada remaja dari ibu pekerja migran dan non migran.

\section{Pembahasan}

\section{Cognitive Reappraisal Pada Remaja dari Ibu Pekerja Migran dan Non Migran}

Hasil analisis independent sample t-test pada strategi cognitive reappraisal menunjukkan bahwa tidak ada perbedaan strategi regulasi emosi yang signifikan antara remaja dari ibu sebagai pekerja migran dan non migran. Hal ini dibuktikan dari rata-rata dari remaja ibu pekerja migran adalah sebesar 31,49 dan remaja dari ibu pekerja non migran adalah 32,69 . Perbedaan tersebut sangat tipis sehingga kehadiran ibu dalam penelitian ini tidak dapat membedakan cara remaja meregulasi emosi dengan menggunakan strategi cognitive reappraisal.

Berdasarkan pekerjaan ibu, remaja dibagi menjadi dua yaitu remaja dari ibu pekerja migran dan non migran. Responden pada penelitian ini melibatkan sebanyak 101 orang responden yang terdiri dari 47 orang remaja dari ibu pekerja migran dan 54 sisanya merupakan remaja dari ibu pekerja non migran. Hasil dari penelitian ini menunjukkan bahwa strategi regulasi emosi cognitive reappraisal lebih banyak digunakan oleh remaja dari ibu pekerja non migran dengan persentase sebesar 83\%. Pada remaja dari ibu pekerja migran yang menggunakan strategi cognitive reappraisal persentasenya adalah sebesar $49 \%$. Pengkategorisasian ini berdasarkan dari jumlah rata-rata tiap strategi regulasi emosi dimana rata-rata yang lebih tinggi menunjukkan penggunaan yang lebih sering, sehingga perbedaan ini tidak cukup terlihat.

Strategi regulasi emosi cognitive reappraisal menurut Gross dan John (2003) adalah suatu bentuk perubahan kognitif yang melibatkan penafsiran situasi yang berpotensi memunculkan emosi dengan cara mengubah dampak emosionalnya. Individu tersebut mengubah pola pikirnya terhadap suatu situasi sehingga apa yang ditampakkan dan apa yang dirasakan oleh individu tersebut akan sama. Dalam hal ini remaja dari ibu pekerja migran dan non migran tampaknya sama-sama baik dalam penggunaan strategi cognitive reappraisal dalam meregulasi emosi. Faktor yang dapat mempengaruhi cara seseorang dalam meregulasi emosi adalah terkait pola pengasuhan dan attachment (Calkins dalam Gross, 2006), jenis kelamin (Nyklicek, Vingerhoets, \& Zeelenberg, 2011), dan juga hubungan interpersonal (Salovey \& Sluyter, 1997).

Tidak adanya perbedaan skor rata-rata pada strategi cognitive reappraisal diasumsikan bahwa pola pengasuhan yang dilakukan oleh pihak selain ibu mungkin efektif dalam penggunaan cognitive reappraisal karena antara remaja dari ibu pekerja migran dan non migran menunjukkan tidak adanya perbedaan. Jenis kelamin diasumsikan juga menjadi salah satu faktor yang dapat mempengaruhi cara seseorang dalam meregulasi 
emosi. Persebaran jumlah persentase antara laki-laki dan perempuan yang tidak sama kemungkinan dapat memberikan hasil yang berbeda pula.

Pada penelitian ini remaja dari ibu pekerja migran kebanyakan tinggal bersama dengan ayah dan juga nenek/kakek. Dari 47 orang responden, 20 orang remaja tinggal bersama dengan ayah, 13 orang tinggal bersama nenek/kakek, 5 orang tinggal bersama paman/bibi, 2 orang tinggal bersama ayah dan nenek/kakek, 3 orang tinggal bersama paman/bibi dan nenek/kakek, 1 orang tinggal bersama ayah tiri dan hanya 3 orang remaja yang tinggal sendiri. Pengasuhan dalam hal ini tidak hanya dipegang oleh ibu akan tetapi juga dapat dipegang oleh ayah dan keluarga besar lain seperti kakek dan nenek atau paman dan bibi, sehingga remaja tetap dalam pengawasan orang yang lebih tua dan tidak dibiarkan untuk tinggal sendiri. Keterlibatan ayah dalam pengasuhan juga dapat memberikan dampak tersendiri dalam perkembangan remaja.

Sejumlah penelitian yang dirangkum oleh Allen dan Daly (2007) membuktikan bahwa keterlibatan seorang ayah dalam pengasuhan berkorelasi positif dengan kehidupan anak secara menyeluruh. Peran keterlibatan seorang ayah juga berdampak pada emosi seperti berkurangnya tingkat depresi anak, tekanan emosional, ekspresi negatif seperti perasaan takut ataupun bersalah. Anak juga dapat mentoleransi keadaan setres dan frustasi, memiliki pemecahan masalah yang baik, lebih ceria, dan lebih mampu mengelola emosi dan impuls mereka dengan cara yang tepat. Gross (2006) juga menyatakan bahwa selain orangtua, teman sebaya dan pengasuh juga memiliki pengaruh dalam pengelolaan cognitive reappraisal.

Selain dari faktor keluarga, jenis kelamin juga menjadi salah satu faktor yang dapat mempengaruhi regulasi emosi seseorang. Pada penelitian ini responden didominasi oleh jenis kelamin perempuan, dimana persentasenya 69\% dari 101 orang responden dan 31\% sisanya merupakan responden laki-laki. Persebaran jumlah jenis kelamin yang tidak seimbang ini memungkinkan memberikan hasil yang berbeda. Penelitian yang dilakukan oleh Ratnasari dan Suleeman (2017) mengenai perbedaan regulasi emosi pada perempuan dan laki-laki di perguruan tinggi. Hasilnya menunjukkan bahwa secara keseluruhan terdapat perbedaan regulasi emosi pada perempuan dan laki-laki.

Menurut Nyklicek, Vingerhoets, dan Zeelenberg (2011) jenis kelamin seseorang juga dapat menjadi salah satu faktor yang dapat mempengaruhi regulasi emosi. Stereotip yang beredar di masyarakat adalah emosi perempuan berbeda dengan emosi laki-laki. Kebanyakan perempuan lebih banyak mengalami emosi dan mengekspresikannya dibanding laki-laki. Di sisi lain laki-laki diyakini biasanya mengubur dan menyangkal emosi mereka. Persepsi perbedaan jenis kelamin dalam respon emosional ini membentuk salah satunya elemen paling kuat dalam stereotip jenis kelamin.

\section{Expressive Suppression Pada Remaja dari Ibu Pekerja Migran dan Non Migran}

Hasil analisis data strategi expressive suppression menunjukkan bahwa terdapat perbedaan strategi regulasi emosi yang signifikan antara remaja dari ibu sebagai pekerja migran dan non migran. Dari nilai mean yang diperoleh terlihat bahwa strategi expressive suppression lebih banyak digunakan oleh remaja dari ibu pekerja migran dibanding mereka yang dari ibu non migran. Remaja yang menggunakan expressive suppression dalam meregulasi emosi cenderung untuk lebih menekan emosinya. Mereka mengubah emosi mereka setelah respon emosi dihasilkan.

Tingginya skor rata-rata strategi expressive suppression pada remaja dari ibu pekerja migran menunjukkan bahwa anak dari pekerja migran rata-rata cenderung untuk lebih menekan emosinya. Mereka mengubah emosi mereka setelah respon emosi muncul, dimana dikhawatirkan hal tersebut dapat memiliki efek samping yang tidak diinginkan dan menekan emosi yang positif ketika digunakan sebagai strategi untuk meregulasi emosi negatif. Penelitian yang dilakukan oleh Gross dan John (2003) menunjukkan bahwa individu yang sering menggunakan expressive suppression dalam meregulasi emosinya 
cenderung memiliki skor well being dan self esteem yang rendah dan juga memiliki lebih banyak simtom depresi.

Pola pengasuhan dan attachment merupakan faktor yang dapat mempengaruhi cara seseorang dalam meregulasi emosi (Gross, 2006) Pada penelitian ini 45\% remaja tinggal bersama ayah dan ibu sedangkan sisanya tinggal dengan ayah atau anggota keluarga yang lain seperti paman/bibi dan nenek/kakek. Pola pengasuhan idealnya dilakukan oleh keluarga yang merupakan lingkungan sosial terkecil namun memiliki peran yang sangat besar dalam mendidik anak (Hasnawati, 2013). Remaja dari ibu pekerja non migran lebih banyak waktu berinteraksi sehingga mereka memiliki attachment dengan ibunya dibandingkan dengan mereka yang memiliki ibu pekerja migran.

Pola pengasuhan yang dilakukan oleh orangtua tunggal dan pengasuh pengganti tentunya akan memiliki dampak yang berbeda. Hal itu terlihat dari hasil penelitian ini dimana strategi expressive suppression cenderung lebih banyak digunakan oleh remaja dari ibu sebagai pekerja migran. Hal yang sama juga ditunjukkan oleh penelitian Choirunissa dan Ediati (2018) dimana terdapat hubungan positif yang signifikan antara komunikasi interpersonal remaja-orangtua dengan regulasi emosi. Semakin tinggi komunikasi interpersonal remaja-orangtua, maka semakin tinggi regulasi emosinya, begitupun sebaliknya.

Dari sini dapat dikatakan bahwa kehadiran ibu masih termasuk salah satu faktor yang dapat mempengaruhi cara seseorang dalam meregulasi emosinya. Pada dasarnya setiap strategi regulasi emosi dapat dimiliki dan digunakan oleh setiap individu dan penggunaannya tergantung dari situasi dan kondisi serta tujuan dari individu tersebut. Skor mean yang lebih besar menunjukkan bahwa penggunaan lebih sering pada salah satu strategi tersebut. Pada penelitian ini terlihat adanya perbedaan yang cukup signifikan pada expressive suppression yang menunjukkan bahwa penggunaan expressive suppression pada remaja ibu pekerja migran yang lebih sering digunakan dalam meregulasi emosi.

Persentase remaja ibu pekerja migran yang menggunakan expressive suppression lebih sering dalam meregulasi emosi adalah sebesar $51 \%$ dan remaja dari ibu pekerja non migran adalah $17 \%$. Hal ini cukup mengkhawatirkan mengingat expressive suppression dapat memiliki efek samping yang tidak diinginkan dan menekan emosi yang positif ketika digunakan sebagai strategi untuk meregulasi emosi negatif. Penelitian yang dilakukan oleh Gross dan John (2003) menunjukkan bahwa cognitive reappraisal lebih direkomendasikan sebagai strategi dalam meregulasi emosi dibandingkan dengan expressive suppression.

\section{Simpulan dan Saran}

Hasil penelitian ini dapat disimpulkan tidak ada perbedaan regulasi emosi yang signifikan pada strategi cognitive reappraisal antara remaja dari ibu pekerja migran dan pekerja non migran. Namun Regulasi emosi pada strategi expressive suppression berbeda secara signifikan antara remaja dari ibu pekerja migran dan pekerja non migran. Saran bagi remaja yang memiliki ibu pekerja baik migran maupun non migran diharapkan dapat menjaga interaksi yang baik. Interaksi mungkin dapat dilakukan melalui media telepon agar komunikasi tetap terjaga. Ibu yang menjadi pekerja migran dapat meminta bantuan sanak saudara dalam pengasuhan anak, agar mereka memiliki teman untuk bercerita. Hal ini berguna dalam mengelola expressive suppression agar regulasi emosi mereka tetap berkembang.

Bagi peneliti selanjutnya diharapkan dapat mempertimbangkan kualitas dan kuantitas interaksi remaja dengan orangtua dan pihak lain seperti paman/bibi atau kakek/nenek. Selain itu faktor lingkungan pada remaja seperti teman sebaya juga dapat menjadi alternatif faktor yang dapat dipelajari lebih lanjut. Proporsi populasi dan 
pengambilan sampel yang lebih representatif juga dapat dilakukan agar hasil penelitian dapat digeneralisasikan secara valid.

\section{Daftar Pustaka}

Allen, Sarah \& Kerry Daly. 2007. The Effect of Fathers Involvement: An Update Research Summary of the Evidence. Guelph: Father Involvement Research Alliance.

Bariola, E, Gullone E \& Hughes E. K. 2011. Relationship Between Parent and Child emotion Regulation Strategy Use: A Brief Report. Journal of Child and Family Studies. Vol 21 (3). DOI 10.1007/s10826-011-9497-5

Choirunissa, R \& Ediati A. 2018. Hubungan antara Komunikasi Interpersonal RemajaOrangtua dengan Regulasi Emosi pada Siswa SMK. Jurnal Empati. Vol 7 (3), 236 243.

Garside, R. B \& Klimes-Dougan B. 2002. Socialization of Discrete Negative emotions: gender Differences and Links With Psychological Distress. Sex Roles. Vol 4 (3/4).

Gross, J. J \& John O. P. 2003. Individual Differences in Two Emotion Regulation Processes: Implications for Affect, Relationship, and Well-being. Journal of Personality and Social Psychology. Vol 85 (2), 348 - 362.

Gross, J. J. 2006. Handbook of Emotion Regulation. New York: The Guilford Press.

Hasnawati. 2013. Pendidikan Akhlak dalam Pola Asuh Orangtua. Jurnal Pendidikan Islam. Vol 28 (3), $441-454$

Lamb, M. E \& Freund A. M. 2010. The Handbook of Life Span Development: Social and Emotional Development (Volume 2). New Jersey: John Wiley \& Sons, Inc.

Martin, A. D. 2003. Emotional Quality Management. Jakarta: Penerbit Arga.

Nyklicek, I., Vingerhoets, A. J. J. M., \& Zeelenberg, M. (Eds.). 2011. Emotion regulation and well-being. New York: Springer.

Ratnasari, Shinantya \& Suleeman J. 2017. Perbedaan Regulasi Emosi Perempuan dan lakilaki di Perguruan Tinggi. Jurnal Psikologi Sosial. Vol 15 (1), 35-46. Doi: 10.7454/jps.2017.4

Santrock, J. W. 2012. Perkembangan Masa Hidup. Terjemahan Benedictine Wisdyasinta. Jakarta: Penerbit Erlangga.

Santrock, J. W. 2013. Adolescence (Fifteenth Edition). New York: McGraw Hill.

Salovey, P \& Sluyter D. J. 1997. Emotional Development and Emotional Intelligence: Educational Implications. New York: Basic Books.

Septiawan, R. R. 2019. Pengaruh Regulasi Emosi dan Penyesuaian Sosial terhadap Kenakalan Remaja pada Siswa SMP Negeri 1 Pageruyung Kendal. Skripsi, Jurusan Bimbingan dan Konseling, Fakultas Ilmu Pendidikan, Universitas Negeri Semarang.

Silitonga, R. S. 2015. Hubungan Pola Asuh Orang Tua dengan Perkembangan Emosional Remaja di Sekolah Menengah Atas (SMA) Negeri 14 Medan. Skripsi, Ners, Keperawatan \& Kebidanan, Universitas Sari Mutiara Indonesia, Medan.

Verzeletti, C, Zammuner V. L, Galli C \& Agnoli S. 2016. Emotion Regulation Strategies and Psychosocial Well-being in Adolescence. Cogent Psychology. Vol 3 (1), DOI: 10.1080/23311908.2016.1199294 